\title{
Inhibitory effects of valproic acid in DNA double-strand break repair after irradiation in esophageal squamous carcinoma cells
}

\author{
NAOKI MAKITA $^{1}$, ITASU NINOMIYA ${ }^{1}$, TOMOYA TSUKADA ${ }^{1}$, KOICHI OKAMOTO ${ }^{1}$, SHINICHI HARADA ${ }^{2}$, \\ SHINICHI NAKANUMA ${ }^{1}$, SEISHO SAKAI ${ }^{1}$, ISAMU MAKINO ${ }^{1}$, JUN KINOSHITA ${ }^{1}$, HIRONORI HAYASHI ${ }^{1}$, \\ KATSUNOBU OYAMA $^{1}$, HISATOSHI NAKAGAWARA ${ }^{1}$, TOMOHARU MIYASHITA ${ }^{1}$, HIDEHIRO TAJIMA ${ }^{1}$, \\ HIROYUKI TAKAMURA ${ }^{1}$, SACHIO FUSHIDA ${ }^{1}$ and TETSUO OHTA ${ }^{1}$
}

\author{
${ }^{1}$ Department of Gastroenterological Surgery, Division of Cancer Medicine, Graduate School of Medical Science and \\ ${ }^{2}$ Center for Biomedical Research and Education, School of Medical Science, Kanazawa University, Kanazawa 920-8641, Japan
}

Received May 18, 2015; Accepted June 15, 2015

DOI: $10.3892 / o r .2015 .4089$

\begin{abstract}
Radiation therapy is one of the most promising therapeutic strategies in unresectable esophageal squamous cell carcinoma (ESCC). The histone deacetylase (HDAC) inhibitor has been shown to enhance radiosensitivity. Valproic acid (VPA) is a well-known drug used to treat seizure disorders and epilepsy, and has been shown to inhibit HDACs. We recently reported that a clinically safe dose of VPA enhances radiation-induced cytotoxicity in human ESCC cells. However, the mechanism of radiosensitizing effect of VPA has not yet been confirmed. The present study examined the effect of VPA on DNA double-strand break (DSB) repair after radiation in the human ESCC cell lines KES, TE9 and TE11 by examining H2AX phosphorylation ( $\gamma \mathrm{H} 2 \mathrm{AX})$ levels as a marker of radiation-induced DSBs. The present study also examined whether VPA inhibited radiation-induced DNA DSB repair by suppressing non-homologous end joining (NHEJ), focusing particularly on the acetylation of Ku70. VPA was shown to prolong $\gamma \mathrm{H} 2 \mathrm{AX}$ levels after irradiation in all three ESCC cell lines. Moreover, prolonged $\gamma \mathrm{H} 2 \mathrm{AX}$ foci formation after irradiation was also observed by immunocytochemistry
\end{abstract}

Correspondence to: Dr Itasu Ninomiya, Department of Gastroenterological Surgery, Division of Cancer Medicine, Graduate School of Medical Science, Kanazawa University, 13-1 Takara-machi, Kanazawa 920-8641, Japan

E-mail: nino@staff.kanazawa-u.ac.jp

Abbreviations: DSBs, DNA double-strand breaks; ESCC, esophageal squamous cell carcinoma; $\gamma \mathrm{H} 2 \mathrm{AX}, \mathrm{H} 2 \mathrm{AX}$ phosphorylation; HDACs, histone deacetylases; HR, homologous recombination; NHEJ, nonhomologous end joining; VPA, valproic acid

Key words: DNA repair, esophageal cancer, valproic acid, histone deacetylase inhibitor, double-strand DNA breaks, Ku70, nonhomologous DNA end joining following VPA pretreatment in KES and TE9 cells. VPA was shown to induce $\mathrm{Ku} 70$ acetylation after irradiation in all three ESCC cell lines. Our results suggest that VPA prolonged radiation-induced DSBs by inhibiting NHEJ in DSB repair pathways in ESCC. VPA could therefore be used as an effective radiosensitizer in ESCC radiotherapy.

\section{Introduction}

Esophageal squamous cell carcinoma (ESCC) is a malignant disease with a poor prognosis. The standard treatment for advanced ESCC patients has been surgical resection, although patients with unresectable ESCC are usually treated by definitive chemoradiotherapy (CRT) (1). Various anticancer agents have been used to enhance the therapeutic effects of radiotherapy (2-4), including cisplatin and 5-fluorouracil $(2,5,6)$. Although favorable outcomes after CRT compared with radiation therapy alone have been reported $(1,7)$, adverse events are also noted, such as pulmonary dysfunction, leukocytopenia, radiation pneumonitis, pericardial effusion, pleural effusion, perforation and stenosis $(8,9)$. Thus, there is a need to both enhance therapeutic effects and reduce radiation-induced adverse events when performing CRT for esophageal cancer.

Histone acetyltransferases (HATs) and histone deacetylases (HDACs) regulate the acetylation and deacetylation of histones, respectively. Core histone acetylation relaxes the chromatin structure and facilitates transcription $(10,11)$. HDACs are involved in the deacetylation of chromatin histone proteins as well as non-histone proteins, which regulate cell differentiation, apoptosis and growth arrest $(12,13)$. HDAC inhibitors act additively or synergistically with conventional cancer therapies such as radiotherapy, and numerous studies have shown that they enhance the radiation sensitivity of various cancer cell lines both in vitro and in vivo (14-23). These effects have been explained as the modulation of cell cycle regulation, particularly G1-phase arrest, the inhibition of DNA synthesis, the suppression of DNA repair pathways, apoptosis and the alteration of chromatin structures by histone hyperacetylation $(16,19,20,24)$. 
Much attention has been given to the suppression of the double-strand break (DSB) repair pathway by HDAC inhibitors, which enhance the radiation sensitivity and accumulation of the sensitive marker of DSBs, H2AX phosphorylation $(\gamma \mathrm{H} 2 \mathrm{AX})$ (19). Homologous recombination (HR) and nonhomologous end joining (NHEJ) are the main pathways by which radiation-induced DSBs are repaired (25-27). Rad51 is a key protein of HR, while NHEJ involves the Ku70/Ku86 heterodimer which binds with strong affinity to broken DNA ends, and recruits the catalytic subunit of DNA-dependent protein kinases (DNA-PKcs). Ku70 functions are regulated by HATs and HDACs, and an increase in $\mathrm{Ku} 70$ expression in cancer cells was found to enhance the DNA DSB repair ability and reduce Bax-mediated apoptosis (28). Ku70 is also a target of some class I, II and III HDACs (29), while the use of HDAC inhibitors led to increased Ku70 acetylation accompanied by a reduced DNA binding affinity, with no disruption to $\mathrm{Ku} 70 / \mathrm{Ku} 80$ heterodimer formation (30). Treatment of a myelogenous leukemia cell line with HDAC inhibitors before irradiation resulted in increased and prolonged expression of $\gamma \mathrm{H} 2 \mathrm{AX}$ repair foci (24).

Valproic acid (VPA), an 8-carbon branched-chain fatty acid, has a well-established efficacy for the treatment of epilepsy and other seizure disorders. VPA was also shown to be an effective inhibitor of HDACs $(31,32)$, and to enhance radiosensitivity in various cancer cell lines (18,33-35). We recently reported a clinically safe dose of VPA that can enhance radiation-induced cytotoxicity in human ESCC cells by chromatin decondensation with histone hyperacetylation and the downregulation of $\operatorname{Rad} 51$ (36). For certain HDAC inhibitors, the acetylation of proteins in NHEJ has been demonstrated to be involved in the inhibition of radiation-induced DSBs repair (37). However, the mechanism underlying the inhibitory effect of VPA with respect to NHEJ in esophageal cancer has not yet been confirmed. The present study therefore examined whether VPA inhibits radiationinduced DNA DSB repair by suppressing NHEJ in human ESCC cells, focusing particularly on the acetylation of $\mathrm{Ku} 70$ by VPA.

\section{Materials and methods}

Cell lines and cell culture. Three human ESCC cell lines were used in the present study. The poorly differentiated ESCC cell line TE9, and the moderately differentiated TE11 cells were provided by Dr Tetsuro Nishihira (Higashimatsuyama Medical Association Hospital, Saitama, Japan). The highly differentiated ESCC cell line KES was established in our laboratory from endoscopic biopsy specimens obtained from a patient carrying highly differentiated ESCC. These cells were seeded in $75-\mathrm{cm}^{2}$ dishes (Becton-Dickinson, Tokyo, Japan) and cultured in $10 \mathrm{ml}$ of medium consisted of RPMI-1640 $\left(\right.$ Gibco $^{\circledR}$, Life Technologies Corp., Tokyo, Japan) supplemented with $10 \%$ heat-inactivated fetal bovine serum (Nichirei Biosciences, Inc., Tokyo, Japan), $100 \mathrm{IU} / \mathrm{ml}$ penicillin and $100 \mu \mathrm{g} / \mathrm{ml}$ streptomycin (Life Technologies Corp.) at $37^{\circ} \mathrm{C}$ in a humidified atmosphere of $5 \% \mathrm{CO}_{2}$. Cells were grown to confluency and harvested by trypsinization with $0.25 \mathrm{mg} / \mathrm{ml}$ trypsin/EDTA (Life Technologies Corp.), then resuspended in culture medium before use.
Reagents and antibodies. VPA was purchased from SigmaAldrich Co. (Tokyo, Japan). Rabbit anti-phospho-histone H2AX (Ser 139) ( $\gamma \mathrm{H} 2 \mathrm{AX})$ (cat. \#9718) and anti-acetylatedlysine monoclonal antibodies (cat. \#9814) were obtained from Cell Signaling Technology Co. Ltd. (Tokyo, Japan). Rabbit monoclonal anti-Ku70 antibody was purchased from Abcam (cat. \#ab92450; Cambridge, UK), and goat anti-rabbit IgG horseradish peroxidase (HRP)-conjugated were purchased from Cell Signaling Technology (cat. \#7074). $\beta$-actin and TATA-binding protein (TBP) were detected as control proteins using rabbit polyclonal anti- $\beta$-actin antibody (cat. \#4967) and rabbit polyclonal anti-TBP antibody (cat. \#8515) (both from Cell Signaling Technology), respectively.

Irradiation. Cells were irradiated by MBR-1520R-3 (Hitachi Medicotechnology, Hitachi, Japan) at a dose rate of $1 \mathrm{~Gy} / \mathrm{min}$. The $\mathrm{X}$ ray-irradiation power output was $125 \mathrm{kV}, 20 \mathrm{~mA}$. Forward-scattered radiation was filtered using a $0.5 \mathrm{~mm} \mathrm{Al}$ and $0.2 \mathrm{~mm} \mathrm{Cu}$ filter.

Immunofluorescent cytochemistry. Cells were cultured on Lab-Tec chamber slides (Nalge Nunc International, Rochester, NY, USA), treated with or without VPA $(0.5 \mathrm{mM})$ for $24 \mathrm{~h}$, then irradiated (6 Gy). Treated cells were fixed in methanol and acetone (1:1) for $1 \mathrm{~min}$ after irradiation at designated timepoints $(0 / 4 / 8 \mathrm{~h})$. After washing in phosphate-buffered saline (PBS), the slides were immersed in methanol containing $0.3 \%$ $\mathrm{H}_{2} \mathrm{O}_{2}$ for 10 min, blocked with $3.3 \%$ normal goat serum in PBS, and incubated with the rabbit monoclonal anti-phospho-histone $\mathrm{H} 2 \mathrm{AX}$ (Ser 139) antibody (1:200) at $4^{\circ} \mathrm{C}$ overnight. Following three washes in PBS, slides were incubated with an anti-rabbit IgG antibody conjugated with Alexa Fluor ${ }^{\circledR} 594$ (cat. \#A11012; Molecular Probes/Invitrogen, Carlsbad, CA, USA) for $1 \mathrm{~h}$ at room temperature in the dark. Nuclei were stained with Hoechst 33258 for $5 \mathrm{~min}$, and slides were observed under an immunofluorescence microscope (Olympus BX50/BX-FLA; Tokyo, Japan).

Quantification of $\gamma H 2 A X$ levels after irradiation. To assess changes in radiation-induced DNA DSB repair, we compared $\gamma \mathrm{H} 2 \mathrm{AX}$ levels in irradiated cells treated with or without VPA $(0.5 \mathrm{mM})$ using western blotting. Cells treated with combination therapy were pre-treated with VPA for $24 \mathrm{~h}$ before irradiation. Cell lysates were collected after irradiation at designated times $(0 / 10 / 30 \mathrm{~min} / 1 / 2 / 4 / 8 \mathrm{~h})$. The protein concentration in each lysate was measured using the Pierce BCA protein assay kit (Thermo Fisher Scientific, Rockford, IL, USA). A sample volume equivalent to $20 \mu \mathrm{g}$ protein from each lysate was loaded on a $10 \%$ polyacrylamide gel (Mini-Protean TGX Precast Gels; Bio-Rad Laboratories Inc., Berkeley, CA, USA) and separated by electrophoresis. Proteins were transferred to polyvinylidene difluoride (PVDF) membranes (Trans-Blot Turbo mini-PVDF Transfer Pack; Bio-Rad Laboratories Inc.), blocked with Tris-buffered saline with Tween-20 Tablets, pH 7.6 (Takara Bio, Inc., Shiga, Japan), then incubated with the rabbit monoclonal anti-phosphohistone H2AX (Ser 139) primary antibody at a 1:1,000 dilution for $10 \mathrm{~min}$ at room temperature. A rabbit polyclonal $\beta$-actin antibody at 1:5,000 dilution was used to detect $\beta$-actin as a control protein. Secondary antibody incubation using goat 


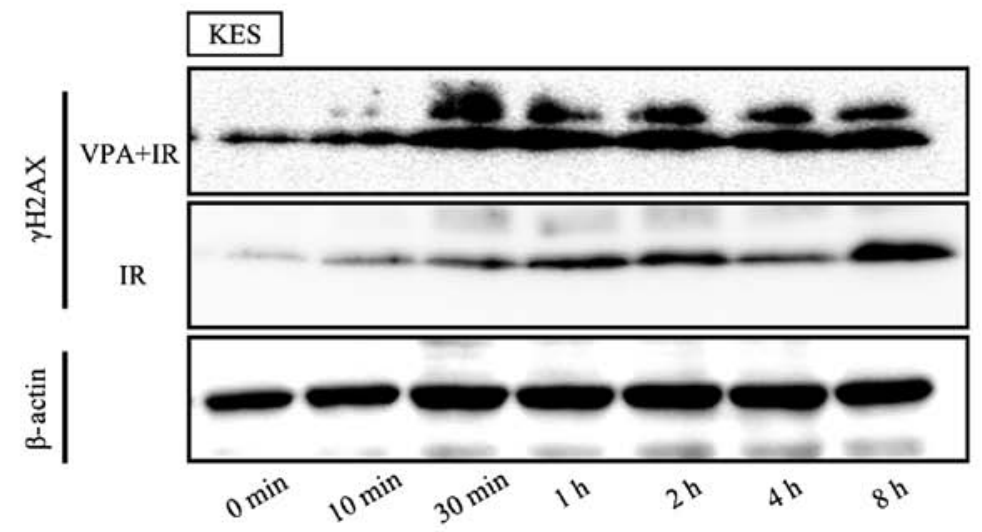

Post-irradiation time

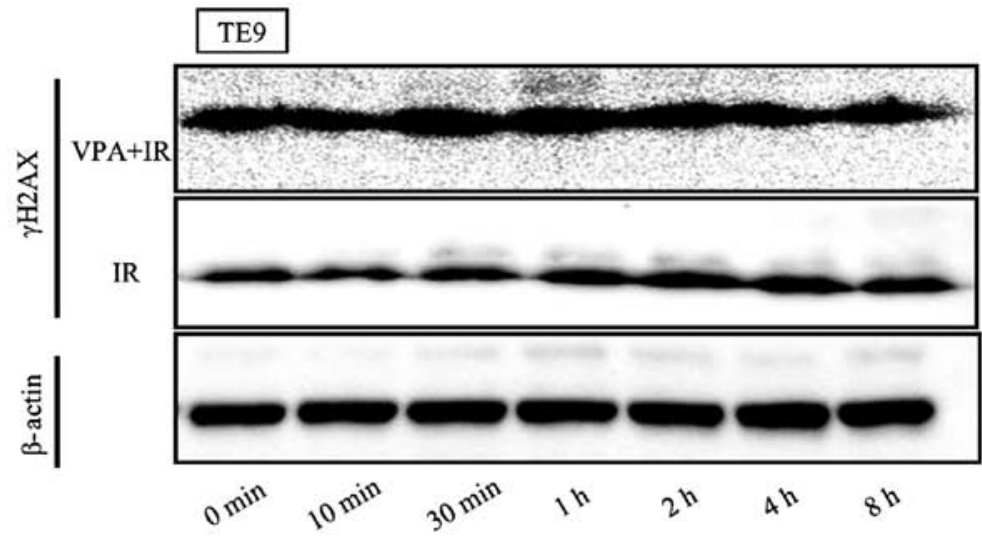

Post-irradiation time

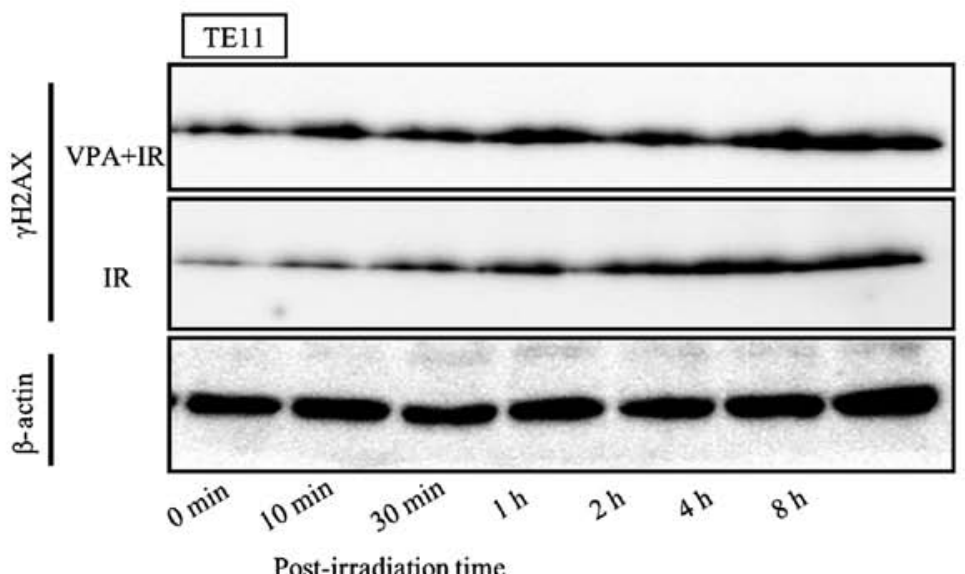

Figure 1. Effects of VPA on radiation-induced DNA DSBs. ESCC cells KES, TE9 and TE11 were cultured with or without VPA $(0.5 \mathrm{mM})$ for $24 \mathrm{~h}$, then irradiated (IR, $6 \mathrm{~Gy})$. $\mathrm{H} 2 \mathrm{AX}$ phosphorylation $(\gamma \mathrm{H} 2 \mathrm{AX})$ levels, as a sensitive marker of radiation-induced DSBs, were determined by western blotting at designated times $(0 / 10 / 30 \mathrm{~min} / 1 / 2 / 4 / 8 \mathrm{~h})$. $\beta$-actin was used as a loading control in each blot. VPA, valproic acid; DSBs, DNA double-strand breaks; ESCC, esophageal squamous cell carcinoma.

anti-rabbit IgG HRP-conjugated at a 1:4,000 dilution was carried out according to the manufacturer's instructions for $10 \mathrm{~min}$ at room temperature (cat. SNAP2BASE; SNAP i.d. 2.0; Millipore, Billerica, MA, USA). Membranes were treated with PVDF Blocking Reagent for Can Get Signal ${ }^{\circledR}$ (Toyobo Co., Ltd., Osaka, Japan). The antibody-antigen complex was detected using enhanced chemiluminescence by an ECL western blotting detection kit (General Electric Healthcare Japan Co., Ltd., Tokyo, Japan) and the Light-Capture system (ATTO Co., Ltd., Tokyo, Japan). Quantification was performed by the CS analyzer program (ATTO Co., Ltd.) and normalized to $\beta$-actin levels.

Assessment of Ku70 acetylation. Cells were incubated with or without VPA $(0.5 \mathrm{mM})$ for $24 \mathrm{~h}$, then irradiated (6 Gy) and harvested promptly. Nuclear proteins were extracted using a Nuclear Extract kit (Active Motif, Tokyo, Japan), and protein concentrations were determined using a Pierce BCA protein assay kit as before. A rabbit monoclonal anti-Ku70 antibody at 1:80 dilution was used for immunoprecipitation. 


\section{KES}

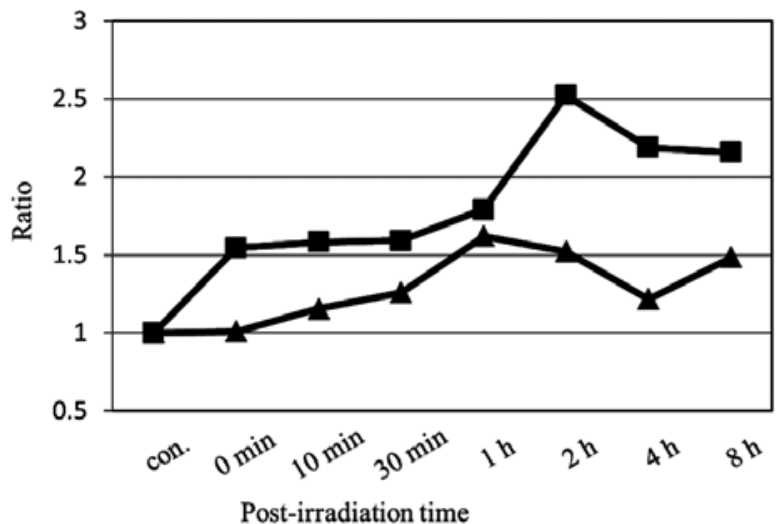

TE11

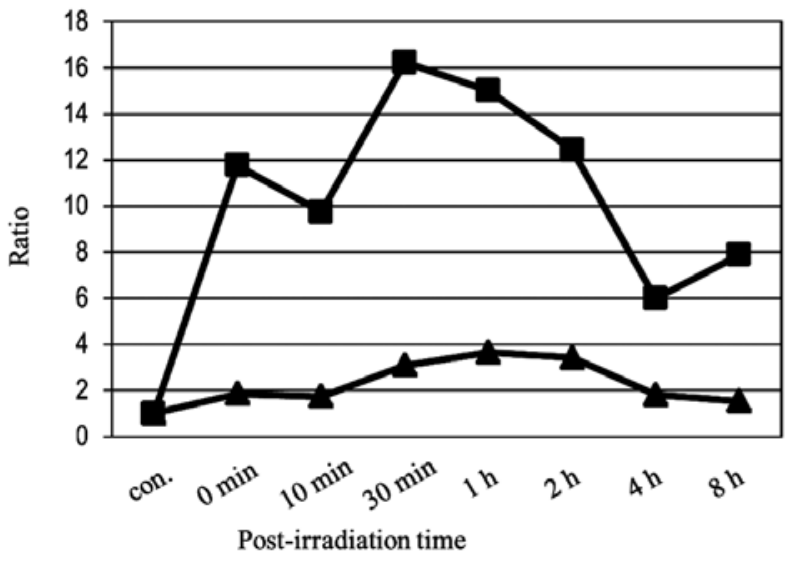

\section{TE9}

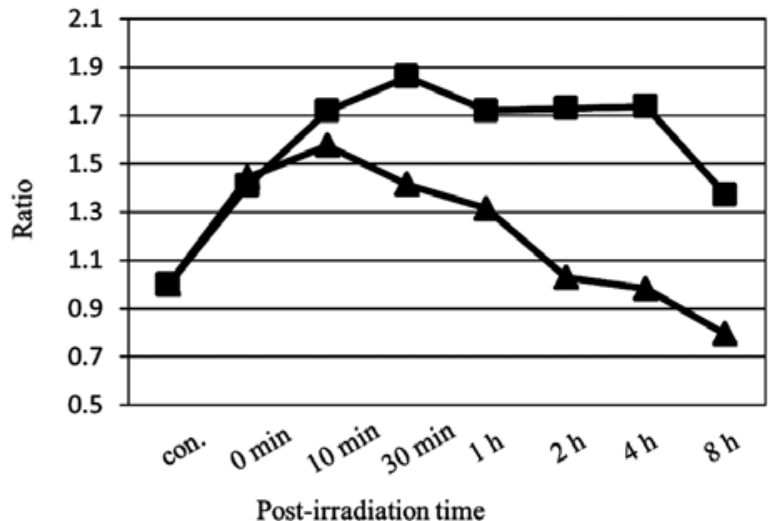

Irradiation (6 Gy) alone
-VPA $(0.5 \mathrm{mM})+$ irradiation $(6 \mathrm{~Gy})$

Figure 2. Time course of the H2AX phosphorylation level changes after irradiation. $\gamma \mathrm{H} 2 \mathrm{AX}$ levels were detected by western blotting in KES, TE11 and TE9 cells cultured with (filled squares) or without (filled triangles) VPA, and were then irradiated. Values were quantified by measuring contrasting densities and calculated as the ratio of $\gamma \mathrm{H} 2 \mathrm{AX}$ to $\beta$-actin. VPA, valproic acid.

Magnetic beads (Dynabeads ${ }^{\circledR}$ Protein G Immunoprecipitation kit; Life Technologies, Carlsbad, CA, USA) were used for immunoprecipitation of the target antigen according to the manufacturer's instructions. The target antibody was incubated with Dynabeads ${ }^{\circledR}$ with rotation for 10 min to enable binding to occur. After adding the extracted nuclear protein to the beads-antibody complex, the sample was incubated at $4{ }^{\circ} \mathrm{C}$ overnight with rotation to form an antigen-beadsantibody complex. The target antigen was dissociated from the beads-antibody complex with elution buffer. Ku70 acetylation was then examined by western blotting using a rabbit monoclonal anti-acetylated-lysine primary antibody at a 1:300 dilution. To detect TBP as a control nuclear protein, a rabbit polyclonal anti-TBP antibody (Cell Signaling Technology) at 1:300 dilution was used. Goat anti-rabbit IgG-HRP conjugates at 1:4,000 dilution were used as secondary antibodies.

\section{Results}

Changes of radiation-induced $\gamma H 2 A X$ levels by VPA. $\gamma \mathrm{H} 2 \mathrm{AX}$ levels in cells pre-treated with VPA were higher than in untreated cells in all three ESCC cell lines (Fig. 1). $\gamma \mathrm{H} 2 \mathrm{AX}$ levels were detected by western blotting and quantified by measuring the ratio of $\gamma \mathrm{H} 2 \mathrm{AX}$ to $\beta$-actin. The time course of $\gamma \mathrm{H} 2 \mathrm{AX}$ is displayed in Fig. 2. VPA was shown to prolong $\gamma \mathrm{H} 2 \mathrm{AX}$ levels after irradiation in all three ESCC cell lines. Moreover, prolonged $\gamma \mathrm{H} 2 \mathrm{AX}$ foci formation after irradiation was also observed by immunocytochemistry following VPA pretreatment in KES and TE9 cells (Fig. 3).

Acetylation of Ku70 by VPA. The acetylation of Ku70 by VPA was estimated by western blotting following immunoprecipitation of the nuclear extract with an anti-Ku70 antibody and the detection of acetylated-lysine. In all three ESCC cell lines, increased $\mathrm{Ku} 70$ acetylation after irradiation was observed following pretreatment with $0.5 \mathrm{mM}$ VPA for $24 \mathrm{~h}$ (Fig. 4).

\section{Discussion}

In the present study, we showed that VPA inhibited the radiation-induced DNA DSB repair in ESCC cell lines, and that this was accompanied by acetylation of the DSB repair protein, $\mathrm{Ku} 70$.

Previously, $\gamma \mathrm{H} 2 \mathrm{AX}$ has been described as a highly sensitive method to detect irradiation-induced DSBs $(38,39)$. In response to this, serine 139 within the conserved C-terminal region of the H2AX protein becomes phosphorylated by one of the DNA damage signaling kinases of the phosphatidylinositol-3-OH- 

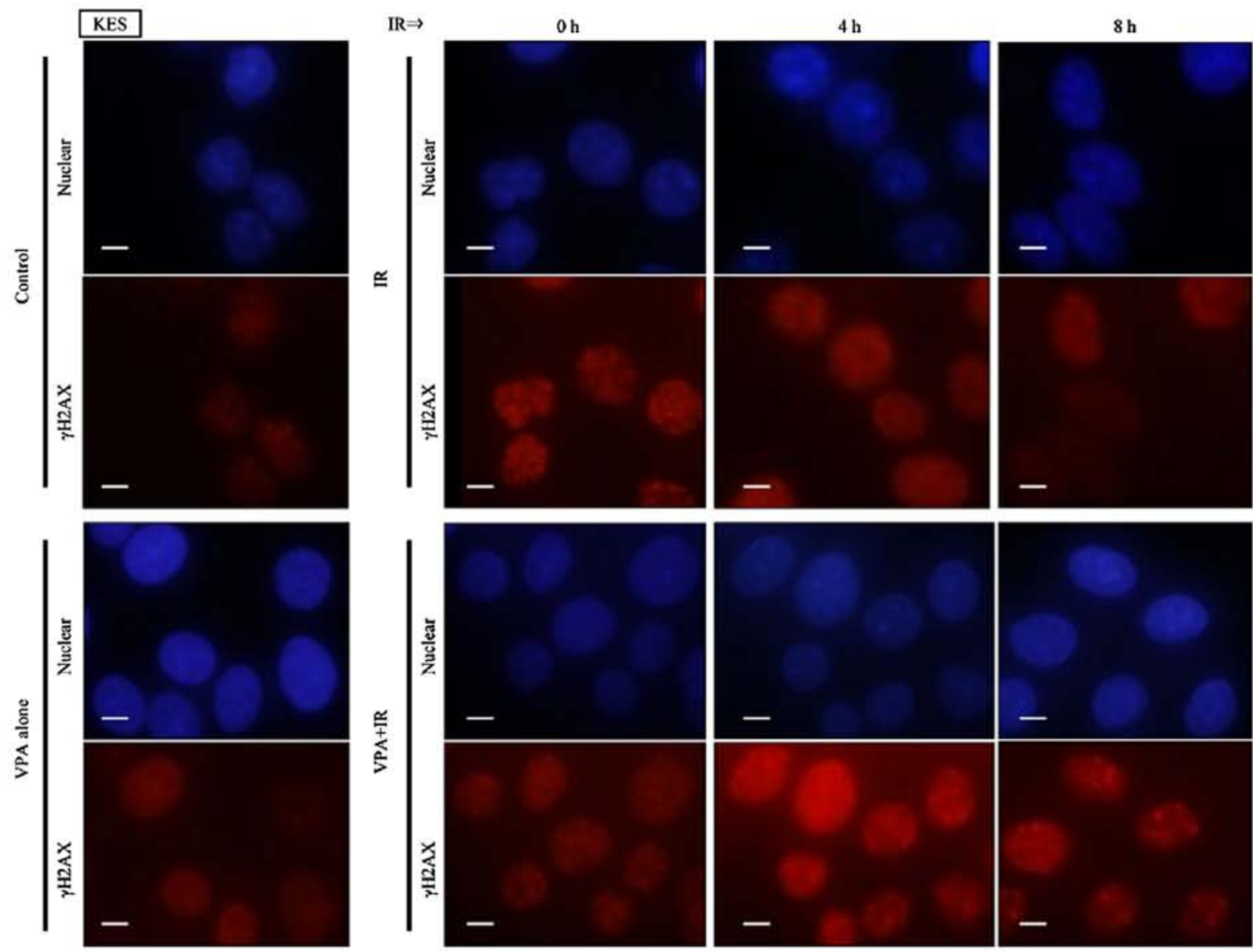

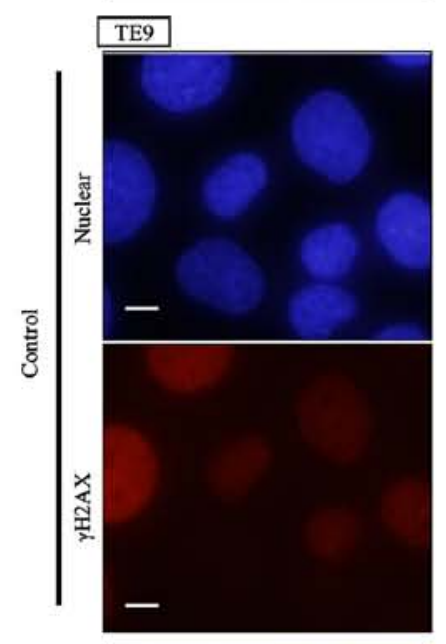

$\mathrm{IR} \Rightarrow$

$0 \mathrm{~h}$
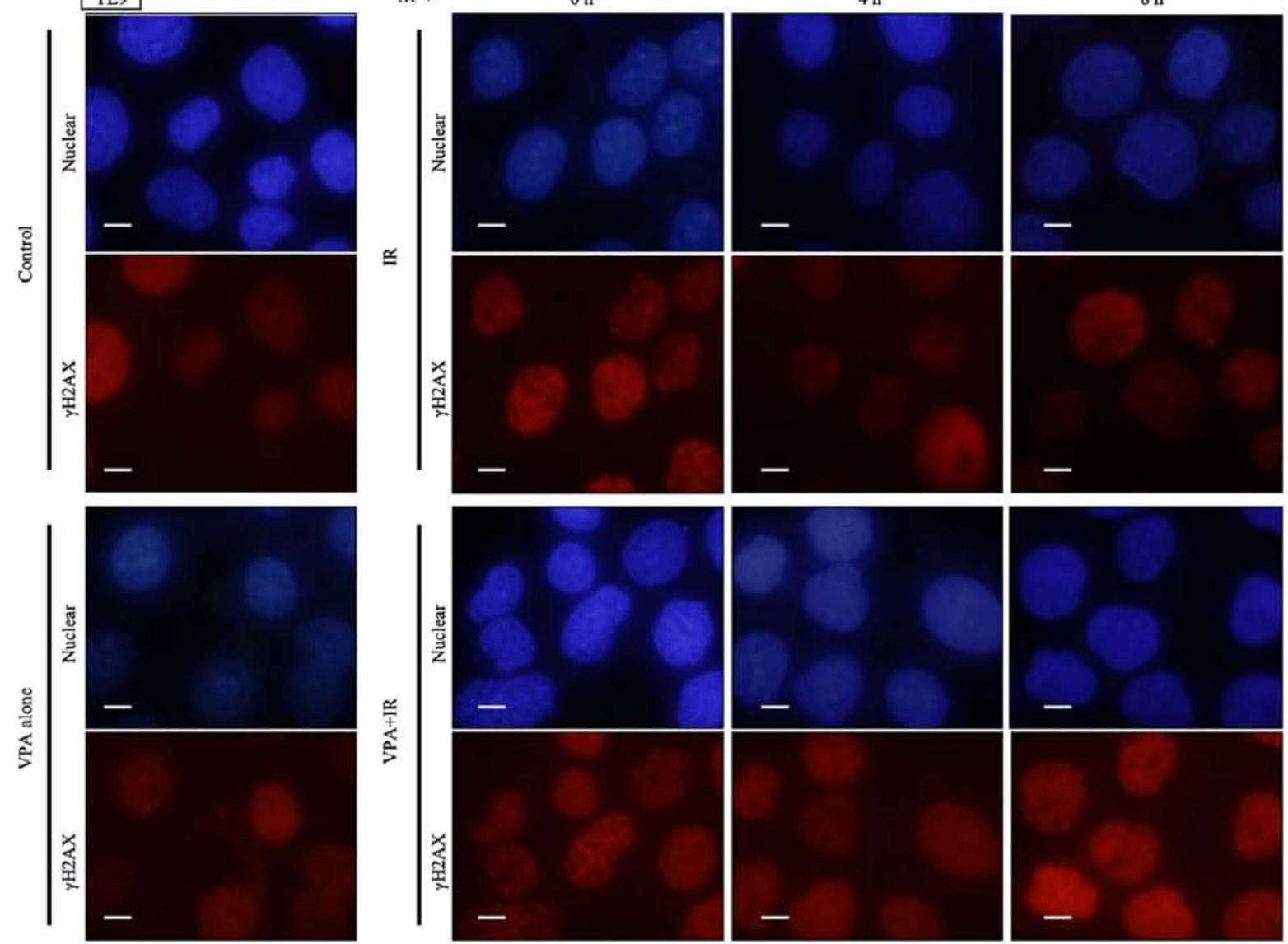

Figure 3. Changes over time in the H2AX phosphorylation foci formation after irradiation, as assessed by immunofluorescent cytochemistry. Micrographs of $\gamma \mathrm{H} 2 \mathrm{AX}$ foci (red) in nuclei (blue) of KES and TE9 cells pre-treated with or without VPA $(0.5 \mathrm{mM})$ for $24 \mathrm{~h} \mathrm{were} \mathrm{obtained} \mathrm{(0} \mathrm{h/4} \mathrm{h/8} \mathrm{h)} \mathrm{after} \mathrm{irradiation} \mathrm{(IR).}$ VPA was shown to prolong $\gamma \mathrm{H} 2 \mathrm{AX}$ foci formation after irradiation. Scale bar, $10 \mu \mathrm{m}$. VPA, valproic acid. 


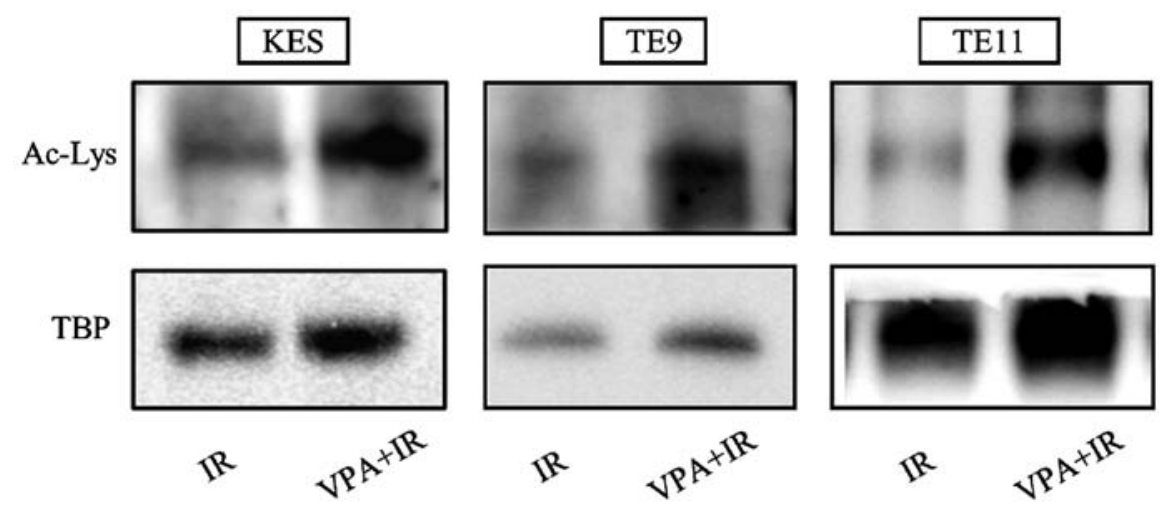

Figure 4. Acetylation of Ku70 by VPA. Esophageal squamous cell carcinoma cell lines (KES, TE9 and TE11) were cultured with or without VPA (0.5 mM) for $24 \mathrm{~h}$, then were irradiated (IR, 6 Gy). Nuclear proteins were extracted from the lysates. Ku70 was separated from the collected nuclear proteins by immunoprecipitation, and its acetylation analyzed by western blotting using an anti-acetylated lysine (Ac-Lys) antibody. TATA-binding protein (TBP) was used as the loading control in each blot. VPA, valproic acid.

kinase-like family. This phosphorylation rapidly spreads to a region of chromatin surrounding the DSBs, resulting in the formation of $\gamma \mathrm{H} 2 \mathrm{AX}$ foci. The main role of H2AX phosphorylation in the DNA damage response was reported to be the recruitment of DNA repair proteins to DSB sites and the preparation of a platform for signaling and repair $(38,40)$. In the present study, we analyzed H2AX phosphorylation levels by western blotting, and examined $\gamma \mathrm{H} 2 \mathrm{AX}$ foci by immunocytochemistry as a marker of DNA DSB after irradiation.

More than 18 mammalian HDAC enzymes (HDAC 1-11 and sirtuins 1-7) have been identified, which are grouped into four classes according to their homology (41). HDAC inhibitors are an emerging class of drugs that have shown promise as anticancer agents when used alone or in combination with conventional therapies $(42,43)$. VPA has been used for the treatment of seizure disorders and epilepsy. Previous studies found that it induces apoptosis and the accumulation of hyperacetylated histones $\mathrm{H} 3$ and $\mathrm{H} 4$, and also inhibits class I HDACs (HDACs 1, 2 and 3) and class II subclass I HDACs (HDACs 4, 5 and 7$)(31,32,44,45)$. Therapeutic plasma concentrations used clinically for epilepsy treatment range from $50-100 \mu \mathrm{g} / \mathrm{ml}$, which is equivalent to $0.3-0.6 \mathrm{mM}$. Therefore, $0.5 \mathrm{mM}$ VPA is a clinically safe concentration (46) that we used in the present study based on our previous growth inhibition assay in which $0.5 \mathrm{mM}$ VPA did not inhibit the growth of ESCC cells (36).

We recently showed that VPA enhanced the radiosensitizing effect by chromatin decondensation with histone hyperacetylation and downregulation of Rad51 (36). Various mechanisms are responsible for this VPA-mediated enhancement in radiosensitivity. Firstly, HDAC inhibitors lead to the acetylation of histone tails, which induces reduction of the electrostatic charge interactions between DNA and histones, permitting access to the chromatin structure in association with chromatin decondensation $(47,48)$. Additionally, Harikrishnan et al (49) reported that euchromatin was more sensitive to radiation-induced DSBs than heterochromatin, and that histone modifications contributed to the radiosensitivity effects of HDAC inhibitors. Thus, they concluded that heterochromatin is more resistant to histone modification and DNA damage. Secondly, HDAC inhibitors inhibit the radiation-induced DNA DSB repair process. In the present study, we confirmed that VPA prolonged radiation-induced DNA DSB repair by measuring $\gamma \mathrm{H} 2 \mathrm{AX}$ level changes overtime after irradiation. This lengthening of DNA DSBs can be attributed to the VPA-induced inhibition of the DSB repair process. While we previously found that Rad51 expression was downregulated by VPA, and Adimoolam et al (37) reported that suberoylanilide hydroxamic acid (PCI-24781) also suppressed Rad51 expression, the mechanism of its suppression by HDAC inhibitors has not been fully clarified. Further studies are therefore necessary to understand this.

The functional inhibition of non-histone proteins by HDAC inhibitors has recently been reported to involve acetylation (30). However, it is difficult to examine the acetylation of non-histone proteins by western blotting due to the lack of an appropriate primary antibody. Recent studies reported that the acetylation of non-histone proteins by HDAC inhibitors induced the functional inhibition of DNA repair activity $(20,30)$. Furthermore, Chen et al (30) found that HDAC inhibitors reduced the DNA end-binding affinity of Ku70 by acetylation. In the present study, we focused on Ku70 as a key protein of NHEJ in the radiation-induced DNA DSB repair pathway. We confirmed that VPA increased Ku70 acetylation levels in three ESCC cell lines.

In DNA DSB repair pathways, ataxia telangiectasia mutated and ataxia telangiectasia related proteins are important components of the DSB signaling cascade. Their activation results in the phosphorylation of downstream substrates, including p53 (50). HDACs can regulate the expression of various genes by direct interaction (13). For instance, p53 is downregulated by HDACs 1,2 and $3(35,51)$ and acetylated by VPA (45), which induces cell cycle regulation, apoptosis and inhibition of DNA DSB repair $(45,50)$. Several proteins inhibit DNA DSBs repair pathways by mediating the resection process of DNA ends $(52,53)$. Thus, VPA inhibits HR in the repair pathway by acetylating Sae2 and Exo1, which are two nucleases involved in resecting DNA ends (54). Our present findings and those of earlier studies showed that VPA has the potential to synergistically inhibit DNA DSB repair pathways by acetylating p53 in the DSB signaling cascade, nucleases involved in DNA end resection and Ku70 in NHEJ, as well as suppressing Rad51 expression levels in HR. VPA may 
therefore be a suitable agent to combine with radiotherapy due to its multiple effects in DNA DSB repair inhibition. Further studies are needed to clarify the precise mechanisms of DNA DSB repair inhibition by VPA in ESCC.

Tomita et al observed a difference in the proportion of HR and NHEJ in DSB repair in chicken B lymphoid cell lines according to the irradiation dose rate. Although both HR and NHEJ were activated following high-dose irradiation $(0.9 \mathrm{~Gy} / \mathrm{min})$, the activation of NHEJ dominated after low-dose irradiation $(1.0 \mathrm{mGy} / \mathrm{min})(55)$. This suggests that the inhibition of NHEJ may be a more effective means of enhancing radiosensitivity, regardless of the radiation dose. Moreover, Karagiannis and El-Osta (50) reported a radiation protection effect associated with HDAC inhibitors. These not only act as radiosensitizers in response to irradiation, but also reduce radiation-induced dermatitis and esophagitis by suppressing the expression of transforming growth factor- $\beta$ and tumor necrosis factor- $\alpha$. Therefore, the concomitant use of VPA with radiation therapy against esophageal cancer has the potential to reduce various radiation-induced adverse effects.

In conclusion, VPA treatment at clinically safe concentrations enhances radiosensitivity by inhibiting both HR and NHEJ in the DNA DSB repair process, and prolonging DNA DSBs. Therefore, VPA has considerable potential as a therapeutic agent for esophageal cancer.

\section{Acknowledgements}

We are grateful to Medical Technologist of Gastroenterologic Surgery, Kanazawa University for their important contributions to the experiments.

\section{References}

1. Herskovic A, Martz K, al-Sarraf M, Leichman L, Brindle J, Vaitkevicius V, Cooper J, Byhardt R, Davis L and Emami B Combined chemotherapy and radiotherapy compared with radiotherapy alone in patients with cancer of the esophagus. N Engl J Med 326: 1593-1598, 1992.

2. Ohtsu A, Boku N, Muro K, Chin K, Muto M, Yoshida S, Satake M, Ishikura S, Ogino T, Miyata Y, et al: Definitive chemoradiotherapy for T4 and/or M1 lymph node squamous cel carcinoma of the esophagus. J Clin Oncol 17: 2915-2921, 1999.

3. Makino I, Ninomiya I, Okamoto K, Kinoshita J, Hayashi H, Nakamura K, Oyama K, Nakagawara H, Fujita H, Tajima H, et al: A pilot study of chemoradiotherapy with weekly docetaxel for thoracic esophageal carcinoma with T4 and/or M1 lymph node metastasis. World J Oncol 2: 252-258, 2011.

4. van Hagen P, Hulshof MC, van Lanschot JJ, Steyerberg EW, van Berge Henegouwen MI, Wijnhoven BP, Richel DJ Nieuwenhuijzen GA, Hospers GA, Bonenkamp JJ, et al; CROSS Group: Preoperative chemoradiotherapy for esophageal or junctional cancer. N Engl J Med 366: 2074-2084, 2012.

5. Kaneko K, Ito H, Konishi K, Kurahashi T, Ito T, Katagiri A, Yamamoto T, Kitahara T, Mizutani Y, Ohtsu A, et al: Definitive chemoradiotherapy for patients with malignant stricture due to T3 or T4 squamous cell carcinoma of the oesophagus. Br J Cancer 88: 18-24, 2003.

6. Ishida K, Ando N, Yamamoto S, Ide H and Shinoda M: Phase II study of cisplatin and 5-fluorouracil with concurrent radiotherapy in advanced squamous cell carcinoma of the esophagus: A Japan Esophageal Oncology Group (JEOG)/Japan Clinical Oncology Group trial (JCOG9516). Jpn J Clin Oncol 34: 615-619, 2004

7. Cooper JSG, Guo MD, Herskovic A, Macdonald JS, Martenson JA Jr, Al-Sarraf M, Byhardt R, Russell AH, Beitler JJ, Spencer S, et al; Radiation Therapy Oncology Group: Chemoradiotherapy of locally advanced esophageal cancer: Long-term follow-up of a prospective randomized trial (RTOG 85-01). JAMA 281: 1623-1627, 1999.
8. Ishikura S, Nihei K, Ohtsu A, Boku N, Hironaka S, Mera K, Muto M, Ogino T and Yoshida S: Long-term toxicity after definitive chemoradiotherapy for squamous cell carcinoma of the thoracic esophagus. J Clin Oncol 21: 2697-2702, 2003

9. Kato K, Muro K, Minashi K, Ohtsu A, Ishikura S, Boku N, Takiuchi H, Komatsu Y, Miyata Y and Fukuda H; Gastrointestinal Oncology Study Group of the Japan Clinical Oncology Group (JCOG): Phase II study of chemoradiotherapy with 5-fluorouracil and cisplatin for Stage II-III esophageal squamous cell carcinoma: JCOG trial (JCOG 9906). Int J Radiat Oncol Biol Phys 81: 684-690, 2011.

10. Vettese-Dadey M, Grant PA, Hebbes TR, Crane-Robinson C, Allis CD and Workman JL: Acetylation of histone H4 plays a primary role in enhancing transcription factor binding to nucleosomal DNA in vitro. EMBO J 15: 2508-2518, 1996.

11. Ura K, Kurumizaka H, Dimitrov S, Almouzni G and Wolffe AP: Histone acetylation: Influence on transcription, nucleosome mobility and positioning, and linker histone-dependent transcriptional repression. EMBO J 16: 2096-2107, 1997.

12. Lindemann RK, Gabrielli B and Johnstone RW: Histonedeacetylase inhibitors for the treatment of cancer. Cell Cycle 3: 779-788, 2004

13. Ropero S and Esteller M: The role of histone deacetylases (HDACs) in human cancer. Mol Oncol 1: 19-25, 2007.

14. Camphausen K, Burgan W, Cerra M, Oswald KA, Trepel JB, Lee MJ and Tofilon PJ: Enhanced radiation-induced cell killing and prolongation of gammaH2 AX foci expression by the histone deacetylase inhibitor MS-275. Cancer Res 64: 316-321, 2004.

15. Camphausen K, Scott T, Sproull M and Tofilon PJ: Enhancement of xenograft tumor radiosensitivity by the histone deacetylase inhibitor MS-275 and correlation with histone hyperacetylation. Clin Cancer Res 10: 6066-6071, 2004.

16. Zhang Y, Jung M, Dritschilo A and Jung M: Enhancement of radiation sensitivity of human squamous carcinoma cells by histone deacetylase inhibitors. Radiat Res 161: 667-674, 2004.

17. Chinnaiyan P, Vallabhaneni G, Armstrong E, Huang SM and Harari PM: Modulation of radiation response by histone deacetylase inhibition. Int J Radiat Oncol Biol Phys 62: 223-229, 2005.

18. Camphausen K, Cerna D, Scott T, Sproull M, Burgan WE, Cerra MA, Fine $\mathrm{H}$ and Tofilon PJ: Enhancement of in vitro and in vivo tumor cell radiosensitivity by valproic acid. Int $\mathbf{J}$ Cancer 114: 380-386, 2005.

19. Karagiannis TC, Harikrishnan KN and El-Osta A: The histone deacetylase inhibitor, trichostatin $\mathrm{A}$, enhances radiation sensitivity and accumulation of gammaH2A.X. Cancer Biol Ther 4: 787-793, 2005.

20. Munshi A, Kurland JF, Nishikawa T, Tanaka T, Hobbs ML, Tucker SL, Ismail S, Stevens C and Meyn RE: Histone deacetylase inhibitors radiosensitize human melanoma cells by suppressing DNA repair activity. Clin Cancer Res 11: 4912-4922, 2005.

21. Jung M, Velena A, Chen B, Petukhov PA, Kozikowski AP and Dritschilo A: Novel HDAC inhibitors with radiosensitizing properties. Radiat Res 163: 488-493, 2005.

22. Chen X, Wong P, Radany E and Wong JY: HDAC inhibitor, valproic acid, induces p53-dependent radiosensitization of colon cancer cells. Cancer Biother Radiopharm 24: 689-699, 2009.

23. Zhang B, Wang Y and Pang X: Enhanced radiosensitivity of EC109 cells by inhibition of HDAC1 expression. Med Oncol 29: 340-348, 2012.

24. Karagiannis TC, Harikrishnan KN and El-Osta A: Disparity of histone deacetylase inhibition on repair of radiation-induced DNA damage on euchromatin and constitutive heterochromatin compartments. Oncogene 26: 3963-3971, 2007.

25. Mahaney BL, Meek K and Lees-Miller SP: Repair of ionizing radiation-induced DNA double-strand breaks by non-homologous end-joining. Biochem J 417: 639-650, 2009.

26. Dobbs TA, Tainer JA and Lees-Miller SP: A structural model for regulation of NHEJ by DNA-PKcs autophosphorylation. DNA Repair 9: 1307-1314, 2010.

27. Botrugno OA, Robert T, Vanoli F, Foiani M and Minucci S: Molecular pathways: Old drugs define new pathways: Non-histone acetylation at the crossroads of the DNA damage response and autophagy. Clin Cancer Res 18: 2436-2442, 2012.

28. Cohen HY, Lavu S, Bitterman KJ, Hekking B, Imahiyerobo TA, Miller C, Frye R, Ploegh H, Kessler BM and Sinclair DA: Acetylation of the $\mathrm{C}$ terminus of $\mathrm{Ku} 70$ by $\mathrm{CBP}$ and PCAF controls Bax-mediated apoptosis. Mol Cell 13: 627-638, 2004.

29. Hassan MK, Watari H, Salah-Eldin AE, Sultan AS, Mohamed Z, Fujioka Y, Ohba Y and Sakuragi N: Histone deacetylase inhibitors sensitize lung cancer cells to hyperthermia: Involvement of Ku70/SirT-1 in thermo-protection. PLoS One 9: e94213, 2014. 
30. Chen CS, Wang YC, Yang HC, Huang PH, Kulp SK, Yang CC, Lu YS, Matsuyama S, Chen CY and Chen CS: Histone deacetylase inhibitors sensitize prostate cancer cells to agents that produce DNA double-strand breaks by targeting Ku70 acetylation. Cancer Res 67: 5318-5327, 2007.

31. Phiel CJ, Zhang F, Huang EY, Guenther MG, Lazar MA and Klein PS: Histone deacetylase is a direct target of valproic acid, a potent anticonvulsant, mood stabilizer, and teratogen. J Biol Chem 276: 36734-36741, 2001

32. Göttlicher M, Minucci S, Zhu P, Krämer OH, Schimpf A, Giavara S, Sleeman JP, Lo Coco F, Nervi C, Pelicci PG, et al: Valproic acid defines a novel class of HDAC inhibitors inducing differentiation of transformed cells. EMBO J 20: 6969-6978, 2001.

33. Karagiannis TC, $\mathrm{Kn} \mathrm{H}$ and El-Osta A: The epigenetic modifier, valproic acid, enhances radiation sensitivity. Epigenetics 1: 131-137, 2006.

34. Chinnaiyan P, Cerna D, Burgan WE, Beam K, Williams ES, Camphausen K and Tofilon PJ: Postradiation sensitization of the histone deacetylase inhibitor valproic acid. Clin Cancer Res 14: 5410-5415, 2008.

35. Chen X, Wong JY, Wong P and Radany EH: Low-dose valproic acid enhances radiosensitivity of prostate cancer through acetylated p53-dependent modulation of mitochondrial membrane potential and apoptosis. Mol Cancer Res 9: 448-461, 2011.

36. Shoji M, Ninomiya I, Makino I, Kinoshita J, Nakamura K, Oyama K, Nakagawara H, Fujita H, Tajima H, Takamura H, et al Valproic acid, a histone deacetylase inhibitor, enhances radiosensitivity in esophageal squamous cell carcinoma. Int J Oncol 40: 2140-2146, 2012

37. Adimoolam S, Sirisawad M, Chen J, Thiemann P, Ford JM and Buggy JJ: HDAC inhibitor PCI-24781 decreases RAD51 expression and inhibits homologous recombination. Proc Natl Acad Sci USA 104: 19482-19487, 2007.

38. Vandersickel V, Depuydt J, Van Bockstaele B, Perletti G, Philippe J, Thierens $\mathrm{H}$ and Vral A: Early increase of radiationinduced $\gamma \mathrm{H} 2 \mathrm{AX}$ foci in a human Ku70/80 knockdown cell line characterized by an enhanced radiosensitivity. J Radiat Res 51: 633-641, 2010

39. Mah LJ, Orlowski C, Ververis K, Vasireddy RS, El-Osta A and Karagiannis TC: Evaluation of the efficacy of radiation-modifying compounds using $\gamma \mathrm{H} 2 \mathrm{AX}$ as a molecular marker of DNA double-strand breaks. Genome Integr 2: 3, 2011.

40. Rogakou EP, Pilch DR, Orr AH, Ivanova VS and Bonner WM: DNA double-stranded breaks induce histone H2AX phosphorylation on serine 139. J Biol Chem 273: 5858-5868, 1998.

41. Barneda-Zahonero B and Parra M: Histone deacetylases and cancer. Mol Oncol 6: 579-589, 2012

42. Erlich RB, Rickwood D, Coman WB, Saunders NA and Guminski A: Valproic acid as a therapeutic agent for head and neck squamous cell carcinomas. Cancer Chemother Pharmacol 63: 381-389, 2009.
43. Tan J, Cang S, Ma Y, Petrillo RL and Liu D: Novel histone deacetylase inhibitors in clinical trials as anti-cancer agents. J Hematol Oncol 3: 5, 2010.

44. Gurvich N, Tsygankova OM, Meinkoth JL and Klein PS: Histone deacetylase is a target of valproic acid-mediated cellular differentiation. Cancer Res 64: 1079-1086, 2004

45. Duenas-Gonzalez A, Candelaria M, Perez-Plascencia C, PerezCardenas E, de la Cruz-Hernandez E and Herrera LA: Valproic acid as epigenetic cancer drug: Preclinical, clinical and transcriptional effects on solid tumors. Cancer Treat Rev 34: 206-222, 2008.

46. Wolff JE, Kramm C, Kortmann RD, Pietsch T, Rutkowski S, Jorch N, Gnekow A and Driever PH: Valproic acid was well tolerated in heavily pretreated pediatric patients with high-grade glioma. J Neurooncol 90: 309-314, 2008.

47. Garcia-Ramirez M, Rocchini C and Ausio J: Modulation of chromatin folding by histone acetylation. J Biol Chem 270: 17923-17928, 1995.

48. Kim MS, Blake M, Baek JH, Kohlhagen G, Pommier Y and Carrier F: Inhibition of histone deacetylase increases cytotoxicity to anticancer drugs targeting DNA. Cancer Res 63: 7291-7300, 2003.

49. Harikrishnan KN, Karagiannis TC, Chow MZ and El-Osta A: Effect of valproic acid on radiation-induced DNA damage in euchromatic and heterochromatic compartments. Cell Cycle 7: 468-476, 2008

50. Karagiannis TC and El-Osta A: The paradox of histone deacetylase inhibitor-mediated modulation of cellular responses to radiation. Cell Cycle 5: 288-295, 2006.

51. Juan LJ, Shia WJ, Chen MH, Yang WM, Seto E, Lin YS and Wu CW: Histone deacetylases specifically down-regulate p53-dependent gene activation. J Biol Chem 275: 20436-20443, 2000.

52. Mimitou EP and Symington LS: Sae2, Exo1 and Sgs1 collaborate in DNA double-strand break processing. Nature 455: 770-774, 2008.

53. Kaidi A, Weinert BT, Choudhary C and Jackson SP: Human SIRT6 promotes DNA end resection through CtIP deacetylation. Science 329: 1348-1353, 2010.

54. Shubassi G, Robert T, Vanoli F, Minucci S and Foiani M: Acetylation: A novel link between double-strand break repair and autophagy. Cancer Res 72: 1332-1335, 2012.

55. Tomita M, Morohoshi F, Matsumoto Y, Otsuka K and Sakai K: Role of DNA double-strand break repair genes in cell proliferation under low dose-rate irradiation conditions. J Radiat Res 49 557-564, 2008. 